\section{Leucine-zipper motif update}

SIR-The leucine-zipper motif, consisting of four to five leucines repeated every seventh amino-acid residue, mediates dimerization of some DNA-binding proteins ${ }^{1-4}$ but has also been found in several other proteins, sometimes adjacent to proposed transmembrane regions ${ }^{5}$. Thus, as has been previously suggested for coiled-coil structures ${ }^{6}$, many proteinprotein interactions may be mediated through leucine zippers, which may actually constitute a subset of the coiledcoil motif ${ }^{2.7}$. We now report the presence of a leucine zipper in each of a set of sequences thought to represent a family of voltage-gated $\mathrm{K}^{+}$channels and suggest its involvement in subunit interactions ${ }^{8}$ that may mediate voltage-dependent opening and closing of the channel.

The figure shows amino-acid sequence alignment of the voltage-gated $\mathrm{K}^{+}$channels from the region containing the leucine-zipper motif. The leucine repeat is fully conserved except in the case of Shaw but the amino-acid substitutions in this case may not prevent subunit association ${ }^{1-4}$.

Interestingly, the leucine-zipper motif in these $\mathrm{K}^{+}$channels is located immediately adjacent to the $\mathrm{S} 4$ domain. This domain is present in virtually all voltagedependent channels and consists of the sequence $\mathrm{Arg}-\mathrm{X}-\mathrm{X}$, repeated 4-8 times (where $\mathrm{X}$ is a hydrophobic amino acid and Arg can be replaced by Lys). It has been suggested that the $\mathrm{S} 4$ region forms an amphipathic transmembrane helix responsible for sensing membrane electrical potential ${ }^{9}$. In the favoured model of voltage-dependent gating, changes in membrane potential result in a translocation of the S4 helix ${ }^{10}$. But no mechanism has been proposed by which this translocation results in opening and closing of the channel.

The intimate association of the leucinezipper motif with the S4 domain suggests that voltage-dependent translocation of the $\mathrm{S} 4$ sequence alters interactions of $\mathrm{K}^{+}$channel subunits through the leucine zipper. This alteration may take place by physically pulling the zipper into or out of the membrane and/or bending it into or out of an $\alpha$-helical configuration. This would impart a voltage dependence to subunit interactions and provide a mechanism by which S4 translocation determines open and closed channel states. We are currently testing this hypothesis using site-directed mutagenesis.

We have also found leucine zippers within the proposed M4 transmembrane segments of at least some ligand-gated channels. $\mathrm{Na}^{+}-$and $\mathrm{Ca}^{2+}$-channel sequences also have leucine-zipper motifs next to their S4 domains. These motifs align with those in $\mathrm{K}^{+}$channels but often contain prolines. It should be noted that $\mathrm{Na}^{+}$and $\mathrm{Ca}^{2+}$ channels contain a large subunit consisting of 4 homology units, each of which is equivalent to a $\mathrm{K}^{+}$channel subunit. Voltage-dependent control of homology domain association mediated by leucine zippers may also play a role in gating of $\mathrm{Na}^{+}$and $\mathrm{Ca}^{2+}$ channels

KEN MCCORMACK

JAMES T. CAMPANELLI MANI RAMASWAMI MATHEW K. MATHEW MARKA. TANOUYE

Division of Biology,

California Institute of Technology,

Pasadena, California 91125, USA

LINDA E. IVERSON

Division of Neurosciences,

Beckman Research Institute of the City of Hope,

Duart, California 91010, USA

BERNARDO RUDY

Department of Physiology and Biophysics, New York University Medical Center, New York, New York 10016, USA

1. Kouzarides, T. \& Ziff, E. Nature 336, 646-651 (1988).

2. Landshultz, W.H., Johnson, P.F. \& MCKnight, S.L. Science 243, 1681-1688 (1988)

3. Gentz, R., Rauscher, F.J., Abate, C. \& Curran, T. Science 243, 1695-1699 (1989).

4. Turner, R. \& Tijan, R. Science 243, 1689-1694 (1989)

5. Buckland, R. \& Wild, F. Nature 338,547 (1989)

6. Cohen, C. \& Parry, D.A.D. Trends biochem. Sci. 11, 245249 (1986)

7. O'Shea, E.K., Rutkowski, R. \& Kim, P.S. Science 243 538-542 (1989)

8. Iverson, L.E. et al. Proc. natn. Acad. Sci. U.S.A. 85 5723-5727 (1988)

9. Guy, H.R. \& Seetharamulu, P. Proc. natn. Acad. Sci. U.S.A. 83, 508-512(1986)

10. Catterall, W.A. Science 242, 50-61 (1988)

11. Kamb, A. et al. Neuron 1, 421-430 (1988)

12. Baumann, A. et al. EMBO J. 7, 2457-2463 (1988)

13. Tempel, B.L. et al. Nature 332, 837-839 (1988).

14. Butler, A. et al Science 243,943-947(1989).

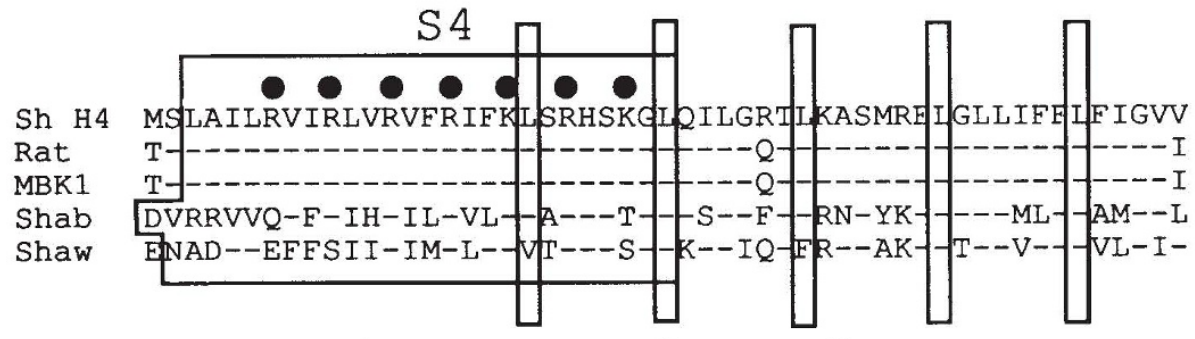

Amino-acid alignment of $\mathrm{K}^{+}$channels. Shaker $(\mathrm{Sh})^{11}$ and the rat ${ }^{12}$ sequences have expressed functional channels in oocytes. The other sequences are from mouse (MBK1) $)^{13}$ and Drosophila (ref. 14). Amino acids identical to Sh are depicted by dashes. Leucines of the proposed zipper are boxed. The $\mathrm{S} 4$ region is also boxed, with circles indicating basic residues in Sh.
SIR-the leucine-zipper motif originally proposed for DNA-binding proteins ${ }^{1}$ has recently been extended to the membrane $\mathrm{F}$ glycoproteins of paramyxoviruses and has been proposed to mediate their oligomerization ${ }^{2}$. In this model, leucine or isoleucine residues are present at exactly seven-residue intervals for at least eight turns of an $\alpha$-helix which facilitates dimerization with a second polypeptide with a similar motif.

We report the presence of this motif in the second membrane-spanning domain of several glucose-transporter glycoproteins. The glucose transporters of vertebrate cells consist of a family of at

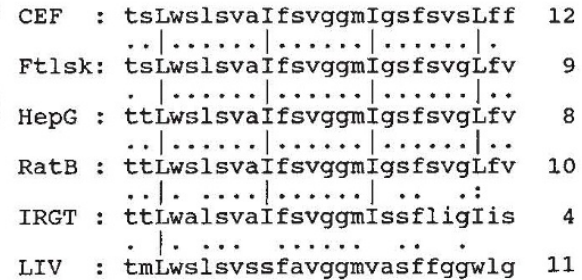

Comparison of leucine-zipper motif regions from different glucose transporters. CEF, chick embryo fibroblast; Ftlsk, human glucose transporter-like protein from human fetal skeletal muscle (type 3); HepG, glucose transporter from HepG2 human hepatoma cells (type 1); RatB, rat brain glucose transporter (type 1); IRGT insulin-regulatable glucose transporter from rat adipocyte (type 4); LIV, glucose transporter from rat liver (type 2). The leucine $(\mathrm{L})$ /isoleucine $(\mathrm{I})$ residues of the proposed zippers are in upper case; double dots indicate the one case where I replaces L; single dots, conserved amino acids.

least four different types of glycoprotein with 12 membrane-spanning domains which differ in tissue distribution and are encoded by discrete genes. As shown in the figure, the leucine-zipper motif occurs in the glucose transporter from chick embryo fibroblasts, which we have partially sequenced, and in all the other published transporter sequences except those from the liver. The sequence similarity in this region is striking considering that the overall sequence similarity between different types of transporters is around 65-70 per cent.

The idea that the glucose transporter dimerizes is attractive for several reasons. First, much direct evidence indicates that glucose-transport activity is associated with a protein that corresponds to the size of a dimer ${ }^{3}$. Second, radiation-inactivation data indicate oligomerization of the functional glucose transporter in vivo ${ }^{4}$. Third, formation of a heterodimer between the insulin-regulatable glucose transporter of insulin-sensitive tissues and brain types of glucose transporter experimentally introduced into such cells could explain why the latter can be regulated by insulin ${ }^{6.7}:$ the heterologous transporter could then ride 'piggy-back' with 